INTERNATIONAL JOURNAL OF RESEARCHES IN BIOSCIENCES, AGRICULTURE AND TECHNOLOGY (C) VISHWASHANTI MULTIPURPOSE SOCIETY (Global Peace Multipurpose Society) R. No. MH-659/13(N) www.vm sindia.org

\title{
OOCYTE DEVELOPMENT IN THE FRESH WATER SPOTTED SNAKEHAD, CHANNA PUNCTATA (BLOCH, 1793)
}

Kulsange B.K. and Masram S.C.

PGTD of Zoology, RTM Nagpur Unive rsity, Nagpur-440033, India suresh.masram@gmail.com

\begin{abstract}
:
Teleosts possesses well defined breeding or re productive cycle. On the basis of shape, size, colour of the ovary diffe rent phases viz., resting phase, early maturing phase, prespawning phase, spawning phase and spent phase are recognized in tele os ts. From the end of resting phase to s pawning phase developing oocytes passes through different stages. During this journey vitellogenesis and maturation is important event for oocyte de velopment. Various stages of female game tes of Channa punctata were analyzed. Mature Channa punctata we re collected by lakes in and around Nagpur city. Different phases of ovarian maturation were confirmed by calculating gondos omatic index (GSI). Ovarian tissues were fixed in Bouin's fixative, de hydrated in graded alcohol, cleared in xylene, embedded in paraffin wax and thus blocks were prepared. Blocks were cut in 6-7 $\mu \mathrm{m}$ thick sections. Sections were stained with Haema toxylene and Eosin (HE). Oocytes morphology was studied in present work. Morphometric analysis of diffe rent oocytes was carried out with help of Tcapture version 4.3.0.602 software.
\end{abstract}

Ke ywords: Channa punctata, oocytes.

\section{Introduction:}

A pair of folded sac like pharyngeal outgrowth provide all the species of the Channa viz., C. punctata, C. marulius, C. striata and C. gachua a te nacity to survive outside the water for considerable period (Chakrabarty, 2006). Oogenesis of teleosts has been thoroughly studied. The various stages of oocytes is based on peculiar morphological, histological, physiological and/or biochemical cell characteristics (i.e. oocyte size, shape, quantity and distribution of diffe rent cytoplasmic as well as nuclear inclusions (Casadevall et al., 1993; Tyle r and Sumpter, 1996). Histological studies of gonad of species reveal gonadal development (West, 1992). Ovarian cycle and spawning season of Ophiocephalus punctatus inhabiting Jammu water was documented (Malhotra et al., 1978) where six stages of oocytes were reported by following method of Srivastava and Rathi (1970). Variation in gonadal cycle, spawning time and spatial behaviour of this fish were well documented (Swaroop, 1954; Belsare, 1962; Malhotra et al., 1978).

\section{Materials and Methods:}

Matured female C. punctata of 150-200

gm weight were procured from various water bodies in and around Nagpur. Fishes were acclaimatized in aquaria for one week. After sacrificing fishes, ovaries were dissected out and fixed in Bouin's fluid. After fixation, ovaries were cutted in pieces and cutted tissues we re washed and transfe rred to $70 \%$ alchohol and dehydrated in graded alcohol, cleared in xylene and embedded in paraffin wax at $60^{\circ} \mathrm{C}-62^{\circ} \mathrm{C}$. Blocks of tissues were trimmed and serial sections of these blocks were cut on Cambridge (rocking) microtome at 6-8 $\mu \mathrm{m}$ thickness in transverse plane. The sections we re fixed on clean slide and later stained by Haematoxylene- Eosine procedure (Lillie, 1965). Sections were observed in Karl Zeiss microscope and photographed by Tucsen USB 2.0 H series camera. Morphometric analys is of differe nt oocytes was carried out with help of Tcapture version 4.3.0.602 software.

Gonado-somatic index was calculated by formula:

$$
\mathrm{GSI}=\left(\mathrm{Wg} \times \mathrm{W}^{-1}\right) \times 100
$$

Where:

Wg-Weight of gonads (g), W- Body weight (g).

Results were expressed as the mean and standard error of mean (SEM). Difference between means were analysed by one-way ANOVA and student T-test. Level of significance was set at $P \leq 0.05$.

\section{Observation:}

Based on GSI, morphology of ovaries and presence of oocyte present identified five phases of reproductive cycle viz., Resting phase (Mid December- February), Early maturing phase (March- April), Prespawning phase (May), Spawning phase (June - October) and Spent phase (Nove mber- Mid December). GSI of resting phase was lowest (0.58 0.04) (Table 1, Graph 1). GSI was slightly higher in early maturing phase $(1.99 \pm 0.9)$ (Table 1, Graph 1). GSI was further significantly rises in prespawning phase $(4.49 \pm 0.89)(p<0.05)$ (Table 1, Graph 1). GSI was maximum in spawning phase and significantly higher than prespawning phase $(p<0.05)(14.41 \pm$ 0.73 ) (Table 1, Graph 1). In spent phase, GSI was lowered significantly to $0.60 \pm 1.03$. No significant difference observed between GSI of resting and spent phase $(\mathrm{p}<0.05)$.

Oogenesis initiated with development and growth of oocytes. Overall six oocyte development stages were identified for $C$. punctata. 
Primary oogonia: With $16.52 \pm 1.4 \mu \mathrm{m}$ these were smallest oval cells (Fig. 1a) (Table 2, Graph 2). Primary oogonias either present singly or they present in cluster. Cytoplasm is strongly basophilic.

Chromatin nucleolus oocytes: These oocytes develop from primary oogonias therefore they were observed in proximity of primary

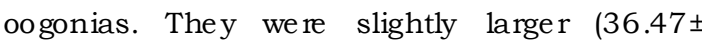
$1.7 \mu \mathrm{m})$ (Table 2, Graph 2). They had a large and lightly stained nucleus. A single nucleolus located towards nuclear me mbrane (Fig. 1b).

Early perinucleolar oocyte: Further growth $(47.62 \pm 0.87 \mu \mathrm{m})$ was observed in early pe rinucleolar oocyte (Fig. 1c) (Table 2, Graph 2). It had slightly less basophilic cytoplasm. Larger, regular rounded nucleus with several small nucleoli were seen towards peripheral margin of nucleoplasm (Fig. 1c).

Late perinucleolar oocyte: Significant growth observed in late perinucleolar oocyte (64.45 \pm 0.87 ) (Fig. 1d) (Table 2, Graph 2). In late perinucleolar oocyte, nucleus become irregular and multiple cortical alveoli appears towards pe riphe ry of cytoplasm (Fig. $1 \mathrm{~d}$ ).

Vitellogenic oocyte: Vitellogenic oocyte is larger than early oocytes stages $(130.46 \pm 1.12)$

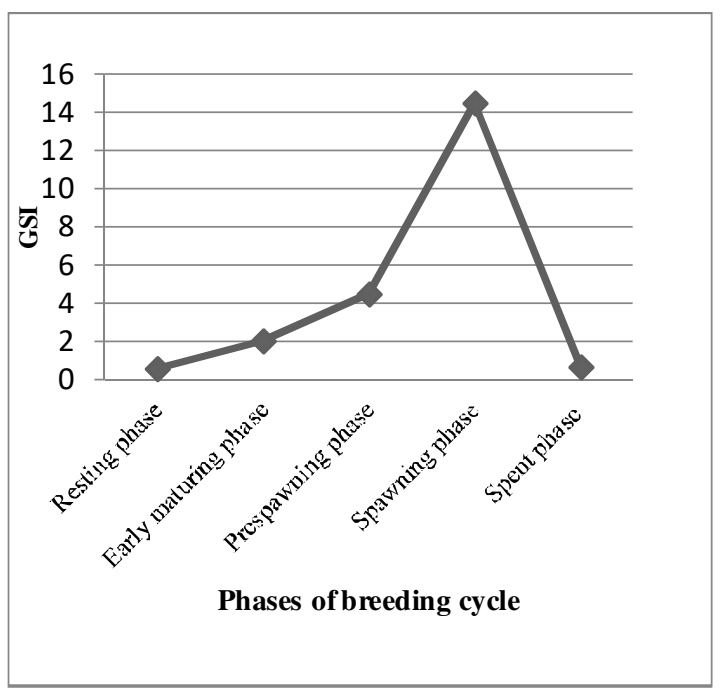

Graph 1: Oscillation in GSI during various phases of breeding cycle
(Table 2, Graph 2). Shrinkage in nucleoplasm observed in vitellogenic oocyte (Fig. 1e). Cytoplasm of vitellogenic oocyte was filled with cortical vesicles (Fig. 1e).

Ripe oocyte: They were largest oocytes (284.99 0.92) (Table 2, Graph 2). Cytoplasm of ripe oocyte was completely filled with cortical vesicles as well as yolk granules. Disintegration of nucleus is complete in ripe oocyte. The cytoplasm of ripe oocyte was more voluminous and had a grainy appearance.

Table 1: GSI in various phases of breeding cycle.

\begin{tabular}{|l|l|}
\hline Ph ase & GSI \\
\hline Re sting phase & $0.58 \pm 0.04$ \\
\hline Early maturing phase & $1.99 \pm 0.9$ \\
\hline Prespawning phase & $4.49 \pm 0.89$ \\
\hline Spawning phase & $14.49 \pm 0.73$ \\
\hline Spent phase & $0.60 \pm 0.02$ \\
\hline
\end{tabular}

Table 2: Morphome tric analysis of oocytes stages in C. punctata

\begin{tabular}{|l|l|}
\hline Oocyte stage & Diameter in $\mu \mathrm{m}$ \\
\hline Primary oogonia & $16.52 \pm 1.4$ \\
\hline Chromatin nucleolus oocyte & $36.47 \pm 1.7$ \\
Early perinucleolar oocyte & $47.62 \pm 0.87$ \\
\hline Late pe rinucleolar oocyte & $64.45 \pm 0.76$ \\
\hline Vitellogenic oocyte & $130.46 \pm 1.12$ \\
\hline Ripe oocyte & $284.99 \pm 0.92$ \\
\hline
\end{tabular}

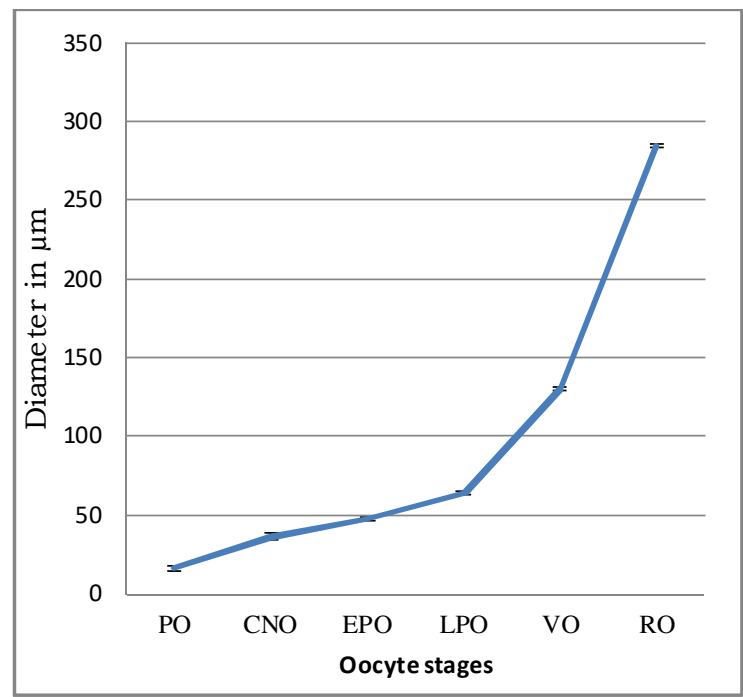

Graph 2: Diameter $(\mu \mathrm{m})$ of oocytes in C. punctata (PO- Primary oogo nia, CNO-Chromatin nucleolus oocyte, EPO-Early perinu cleolar oocyte, LPO-Late perinucleolar oocyte, VO-Vitellogenic oocyte, RORipe oocyte) 


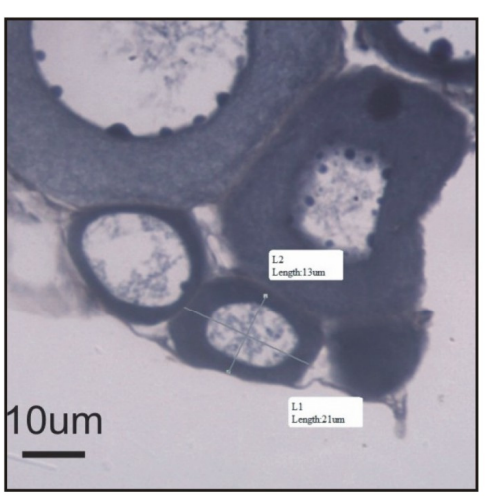

Fig. 3a

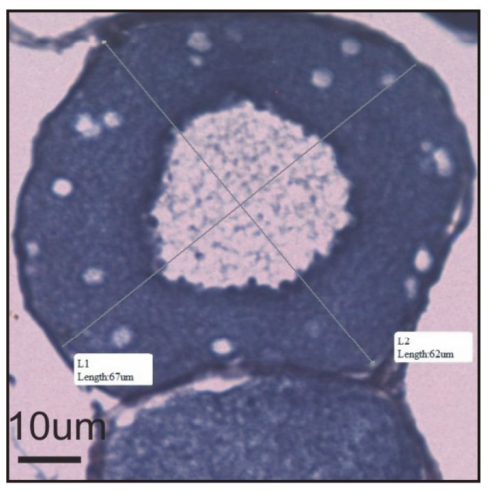

Fig. 3d

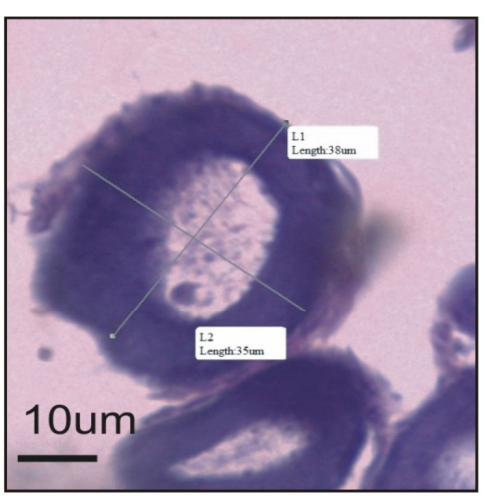

Fig.3b

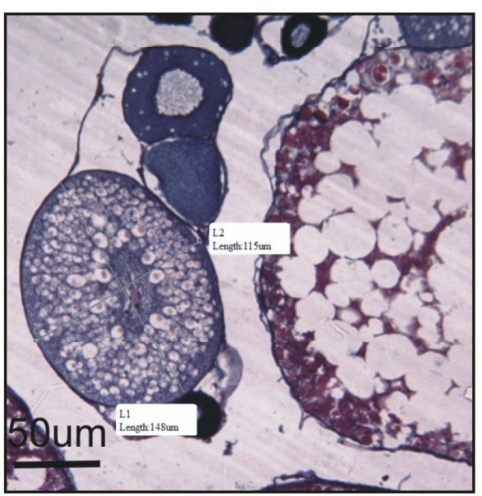

Fig. $3 e$

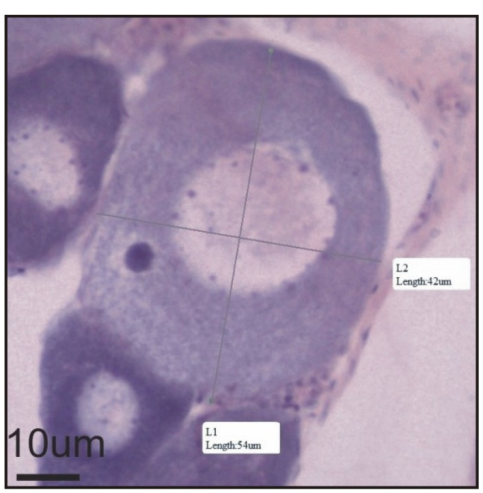

Fig. 3c

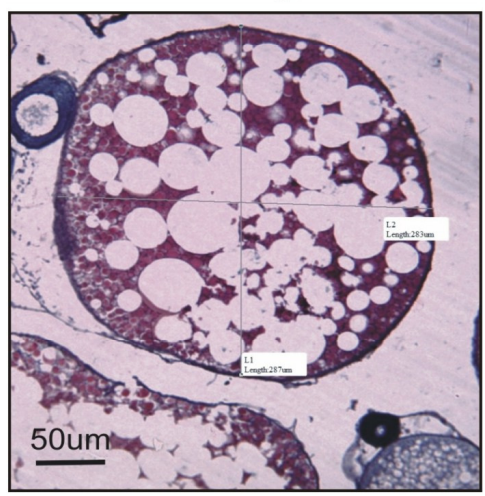

Fig. $3 f$

Fig. 3 Various oocyte stages in C. punctata.

Fig. 3a.Primary oogonia.

Fig. 3b Chromatin nucleolus oocyte.

Fig. 3c Early perinucleolar oocyte.

Fig. 3d Late perinucleolar oocyte.

Fig. 3e Vitellogenic oocyte.

Fig. 3f. Ripe egg

\section{Discussion:}

Recently, oocyte stages in teleosts is studied in perspective of oogenesis. This approach to study the oocyte stages widely used by many authors (Saeed et al., 2010; Higas hino et al., 2000). Five to eight stages of oocyte were reported in teleost fish (Fishelson et al., 1996; Unal et al., 1999; Gokee et al., 2003). Seven stages of oocytes were re ported in Mystus tengara (Mayor et al., 1988) and in Dicentrachus labrax (Brandao et al., 2003) respectively. Six oocyte stages we re reported in present study.

GSI is correlated with gonadal development (Rae and Calvo, 1995; Zimmerman 1997; Koya et al., 1998). Maximum GSI was reported during spawning phase. Similar reports were describe in Cynoglossus arel and C. lida (Rajguru, 1992), Potogonotothen tesselata (Rae

and Calvo, 1995) and in rainbow trout, Oncorhynchus mykiss (Sharma and Bhat, 2014).

Cystovarian type of ovary was exhibited by C. punctata as central lumen of ovary continue posteriorly with lumen of oviduct (Hoar, 1969). Semi cystovarian type of ovary present in Salmoniformes whose gonad open to the coelomic cavity, with oocytes being expelled by funnels (Narahara, 1981)

Different terminology were ascribe to different stages of oogenesis. In spite of using Roman numerals to describe oocyte stages terminology used in Oncorhynchus mykiss was used in present study (Sharma and Bhat, 2014).

Present study confirm the subsequent growth of oocyte from primary oogonia to ripe oocyte. Each stage is significantly larger than previous oocyte stage $(\mathrm{P}<0.05)$. Similar results were found in common carp (Shirali et al., 2012), 
Oreochromis niloticus (El-Saba et al., 2013) and in Oncorhynchus mykiss (Sharma and Bhat, 2014)

\section{Acknowledgement:}

The author acknowledges UGC, New Delhi for financial as sistance under Rajiv Gandhi National Fellowship (F-1-17.1/2013-14/RGNF2013-14-ST-MAH-37551(SA-III/ Website). The author also acknowledges support and facility provided by PGTD of Zoology, RTM Nagpur University, Nagpur.

References:

Belsare DK (1962). Seasonal changes in the ovary of Ophiocephalus punctatus. Indian Quarterly Journal of Fisheries, 9:149-157.

Brando CAS, Valentin MDM, Caromaschi EP (2003). Ovary maturation stages and oocyte features in three species of the neotropical fish Hemiodus spp. Brazilian Archieve of Biology and Technology, 46:3-35.

Casadevall M, Bonet S, Matallanas J (1993). Description of different stages in Ophiodon barbatum (Pisces, Ophiidae). Environmental Biology of Fis hes, 36: 127-133.

Chakrabarty NM (2006). Murrels and murrel culture, Nare ndra Publishing House. New Delhi.

E1-Saba A, Abd Rabou MI, E1- Sakhawy MA, E1Shammaa MA, Hussein SM (2013). Seasonal changes in the histology of the ovaries of Nile tilapia Oreochromis niloticus. Journal of Ve te rinary Anatomy, 6(2):1-21.

Fishels on I, Goren M, Van Vuren J, Manelis R. (1996). Some aspects of the reproductive biology of Barbus spp., Capoeta daascina and their hybrids (Cyprinidae, Teleostei) in Is rael. Hydrobiologia, $317: 79-88$.

Gokee MA, Cengizier I, Ozak AA (2003). Gonad histology and spawning pattern of the white grouper (Epinephelus aeneus) from Iskenderun Bay (Turkey). Turk Journal of Veterinary and Animal Science, 27: 957-964.

Hoar WS (1969). Reproduction. In: W.S. Hoar and D.J. Randall, Fish Physiology. Academic Press, London, 3: 1-72.

Koya YT, Itazu T, Inque $\mathbf{M}$ (1998). Annual reproductive cycle based on his tological changes in the ovary of the female mosquitofish, Gambusia affin is in central Japan. Ichthyological Re search, 45: 241-248.

Lillie RD (1965). Histopathologic technic and practical histochemistry, 3rd edition, McGrawHill Book Co., New York.

Malhotra YR, Jyoti MK and Gupta K (1978). Ovarian cycle and spawning season of Ophiocephalus punctatus, inhabiting Jammu waters, India. Japanese Journal of Ichthyology, 25(3): 1978
Mayor I, Shackely SE, Ryland JS (1988). Aspects of reproductive biology of Dicentrachus labrax. In: A histological study of oocyte development. The Fisheries Society of British Isle s. Garland Publishers, London.

Narahara MY (1991). His to fisiologia do ovario de telesosteos. In: MY Narara (eds.) .Histologia de peixes. FUNEP, Jaboticabal, 77p.

Sharma RK and Bhat RA (2014). Histoarchitectural variations during oocyte growth in rainbow trout (Oncorhynchus mykiss). International Journal of Fisheries and Aquatic Studies, 2(2): 177 - 183

Shirali S, Erfani MN, Mesbah M. Seofoabad Sjappro MR (2012). Histological studies of common carp ovarian development during $b$ reeding season in Khouzestan Province, Iran. World Journal of Fish and Marine Sciences, 4(2): 159-164.

Shrivastava PN and Rathi SK (1970). Effect of radiation on reproductive system of Indian catfish Heteropneustus fossilis Bloch. I. Annual cycle in development of reproductive tissue of Mugil cephalus L. Zoolo gia, 44: 53-70.

Swaroop H (1954). The development of chondrocranium of Ophiocephalus punctatus. Sang University Journal, $1: 61-79$.

Tyler CR and Sumpter JP (1996). O ocyte growth and development in teleosts. Review of Fish Biology and Fishe ries, 6: 287-318.

Unal G, Cetinkaya O, Elp M (1999). Histological investigation of gonad development of Chalcalburnus tarichi. Turkey Journal of Zoology, 23(1):329-338.

West G (1992). Methods of assessing ovarian development in fishes: a review, Australian Journal of Marine and Fresh Water Research, 41: 199-222.

Zimmermann M (1997). Maturity and fecundity of arrowtooth flounder, Atheresthes stomias from the gulf of Alaska. Fis h Bulle tin, 95, 598-611. 